\title{
Successful Detection and Removal of Predictable Juvenile Polyp: Case Report
}

\author{
Kwang Yeon $\mathrm{Kim}^{1}$, Jin Su Kim ${ }^{2}$ \\ ${ }^{1}$ Department of Pediatrics, Eunpyeong St. Mary's Hospital, College of Medicine, The Catholic University of Korea, Seoul; ${ }^{2}$ Division of \\ Gastroenterology, Department of Internal Medicine, Eunpyeong St. Mary’s Hospital, College of Medicine, The Catholic University of Korea, \\ Seoul, Korea
}

Juvenile polyp makes up $70 \%$ to $80 \%$ of pediatric colon polyp, and the average age of diagnosis is 2 to 5 years. The treatment of juvenile polyp in children is polypectomy through colonoscopy. The fact that the lumen of intestine is much smaller than that of adults and the need to perform polypectomy is a heavy burden on the endoscopists. Recently, fecal calprotectin (FC) has been found to be related to juvenile polyp. A previously healthy, 34-month-old female presented to the pediatric department of gastroenterology with intermittent bloody stools which were getting worse. FC level was abnormally elevated at $2,719 \mu \mathrm{g} / \mathrm{g}$ (normal, $<50 \mu \mathrm{g} / \mathrm{g}$ ). The polyp was successfully removed with a polypectomy. This is the first case in Korea to show that FC can be used to screen juvenile polyp in children. FC levels can increase with the degree of inflammation regardless of the number or size of the polyp.

Keywords: Colonoscopy; Polyps; Pediatrics; Ultrasonography

\section{INTRODUCTION}

Juvenile polyp is a type of polyp found mainly in the colon of children, and it occurs in about $2 \%$ of all children. Juvenile polyp makes up $70 \%$ to $80 \%$ of pediatric colon polyp, of which $60 \%$ to $70 \%$ are solitary. The average age of diagnosis of polyp is from 2 to 5 years $[1,2]$. The most common clinical symptom of juvenile polyps is intermittent and self-limiting gastrointestinal bleeding, but polyps in children are often accompanied by abdominal pain. These polyps usually have a pedunculated shape, and polyps with large peduncles can be pushed up and cause intussusception [2]. The treatment of juvenile polyp in children is polypectomy through colonoscopy. Colonoscopy is widely used in pediatric

Received: Apr 29, 2021 - Revised: Jun 7, 2021 - Accepted: Jun 8, 2021 Correspondence to: Jin Su Kim, M.D.

Division of Gastroenterology, Department of Internal Medicine, Eunpyeong St. Mary's Hospital, College of Medicine, The Catholic University of Korea, 1021 Tongil-ro, Eunpyeong-gu, Seoul 03312, Korea

Tel: +82-2-2030-4314, Fax: +82-2-2030-2536

E-mail: jinsu23@naver.com

ORCID: https://orcid.org/0000-0002-3397-3189

(c) 2021 The Korean Society of Coloproctology

This is an open-access article distributed under the terms of the Creative Commons Attribution NonCommercial License (https://creativecommons.org/licenses/by-nc/4.0) which permits unrestricted noncommercial use, distribution, and reproduction in any medium, provided the original work is properly cited. patients but requires a thorough bowel preparation before the examination and general anesthesia or deep sedation during the examination, and in rare cases can cause complications [3]. If there is a way to predict polyps in children through a noninvasive method, it can play an important role in selecting patients who need polypectomy. Fecal calprotectin (FC), which was used in the screening and monitoring of inflammatory bowel disease (IBD), serves as a potential noninvasive biomarker to evaluate the need of endoscopy for juvenile polyp in pediatric $[4,5]$.

Here we report the first case of juvenile polyp in Korean children diagnosed and treated with FC. Informed consent was obtained from the patient, and the case was approved by the Institutional Review Board of Eunpyeong St. Mary's Hospital (No. PC20ZISI0158).

\section{CASE REPORT}

A previously healthy, 34-month-old female presented to the pediatric department of gastroenterology in November 2020 with intermittent bloody stools which were getting worse since June 2019. The patient complained of mild abdominal pain intermittently, and the appearance of the stool was a mixture of blood and tissue. There were no accompanying symptoms such as vomiting, diarrhea, weight loss, fever, and dehydration. The patient visited a 
local clinic and took medicine under suspicion of constipation. Symptoms did not improve and the amounts of bloody stools gradually increased.

The initial vital signs were as follows; blood pressure, 101/60 mmHg; heart rate, 93 beats per minute; respiratory rate, 22 breaths per minute; and temperature, $36.5^{\circ} \mathrm{C}$. She weighed $11.1 \mathrm{~kg}$ and physical examination showed mild periumbilical tenderness without rebound tenderness. A digital rectal exam was performed and there was no palpable mass.

Initial laboratory evaluation showed a hemoglobin concentration of $13.2 \mathrm{~g} / \mathrm{dL}$, white blood cell count of $8,800 / \mu \mathrm{L}$ (neutrophils, $26 \%$ ), and platelet count of $354 \times 10^{3} / \mu \mathrm{L}, \mathrm{C}$-reactive protein of 0.11 $\mathrm{mg} / \mathrm{dL}$, erythrocyte sedimentation rate of $4 \mathrm{~mm} / \mathrm{hr}$, total protein of $6.8 \mathrm{~g} / \mathrm{dL}$, albumin of $4.19 \mathrm{~g} / \mathrm{dL}$, prothrombin time international normalized ratio of 1.08 , and activated partial thromboplastin time of 32.8 seconds, which were in normal length. The serum electrolytes, creatinine, and liver function tests were all within normal limits. Helicobacter pylori immunoglobulin G was negative and stool culture was normal, but occult blood test was increased to $387 \mathrm{ng} / \mathrm{mL}$. FC level was abnormally elevated at 2,719 $\mu \mathrm{g} / \mathrm{g}$ (normal, $<50 \mu \mathrm{g} / \mathrm{g}$ ). Abdominal ultrasonography revealed a single $1.9 \times 1.2-\mathrm{cm}$ oval pedunculated shape mass at the left lower colon (Fig. 1). Under the impression of juvenile poly, colonoscopy was performed using an electronic video endoscope (type GIFH290, Olympus Optical, Tokyo, Japan). Midazolam $0.1 \mathrm{mg} / \mathrm{kg}$ was administered before the colonoscopy for deep sedation, and heart rate, respiration rate, and blood pressure were monitored for the patient's safety. The polyp was a pedunculated type and was located $18 \mathrm{~cm}$ above the anal verge (Fig. 2A). A combination of saline and indigo carmine was used for the submucosal lift (Fig. 2B). The polyp was successfully removed with a polypectomy snare (current $20 \mathrm{~W}$ for excision, Fig. 2C). Three clips were applied to the resected site to prevent delayed bleeding after polypectomy (Fig. 2D). There were no additional polyps in the entire

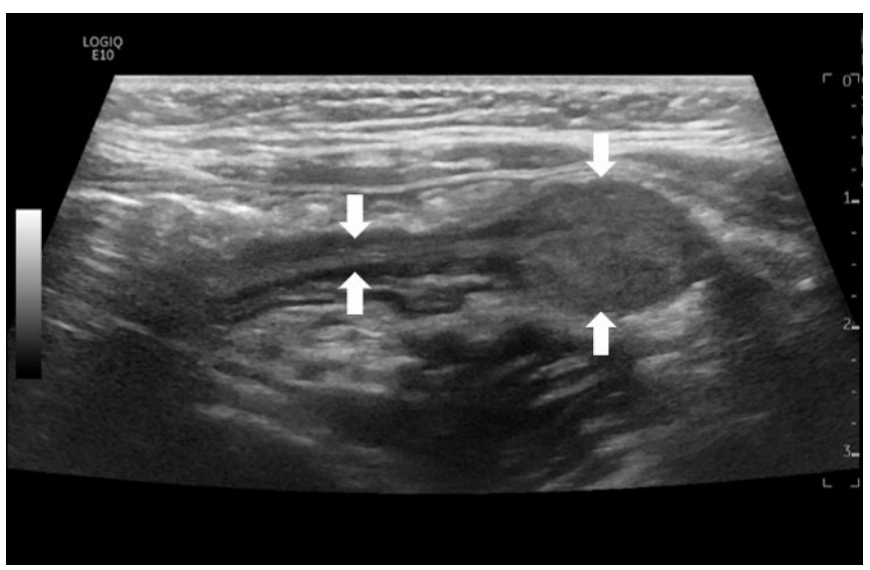

Fig. 1. Abdominal ultrasonography revealed a single $1.9 \times 1.2-\mathrm{cm}$ oval pedunculated shape mass at the left lower colon (arrows). colon (Fig. 2E), and the polyp was retrieved for histological analysis (Fig. 2F), resulting in juvenile polyp with severe inflammation (Fig. 3). There were no complications after polypectomy and the patient was discharged 2 days later. One month after polypectomy, FC levels normalized to less than $50 \mu \mathrm{g} / \mathrm{g}$, and the patient had no bloody stool or other gastrointestinal problems.

\section{DISCUSSION}

Calprotectin is known as an antimicrobial protein and mainly constitutes up to $60 \%$ of the proteins in the cytoplasm of neutrophils [6]. In addition, it is distributed in the cytoplasm of monocytes, macrophages, and granulocytes [7]. FC is mainly used in screening and monitoring IBD patients such as Crohn disease and ulcerative colitis. The mechanism of calprotectin release into the gastrointestinal is activated by increasing leukocyte recruit-
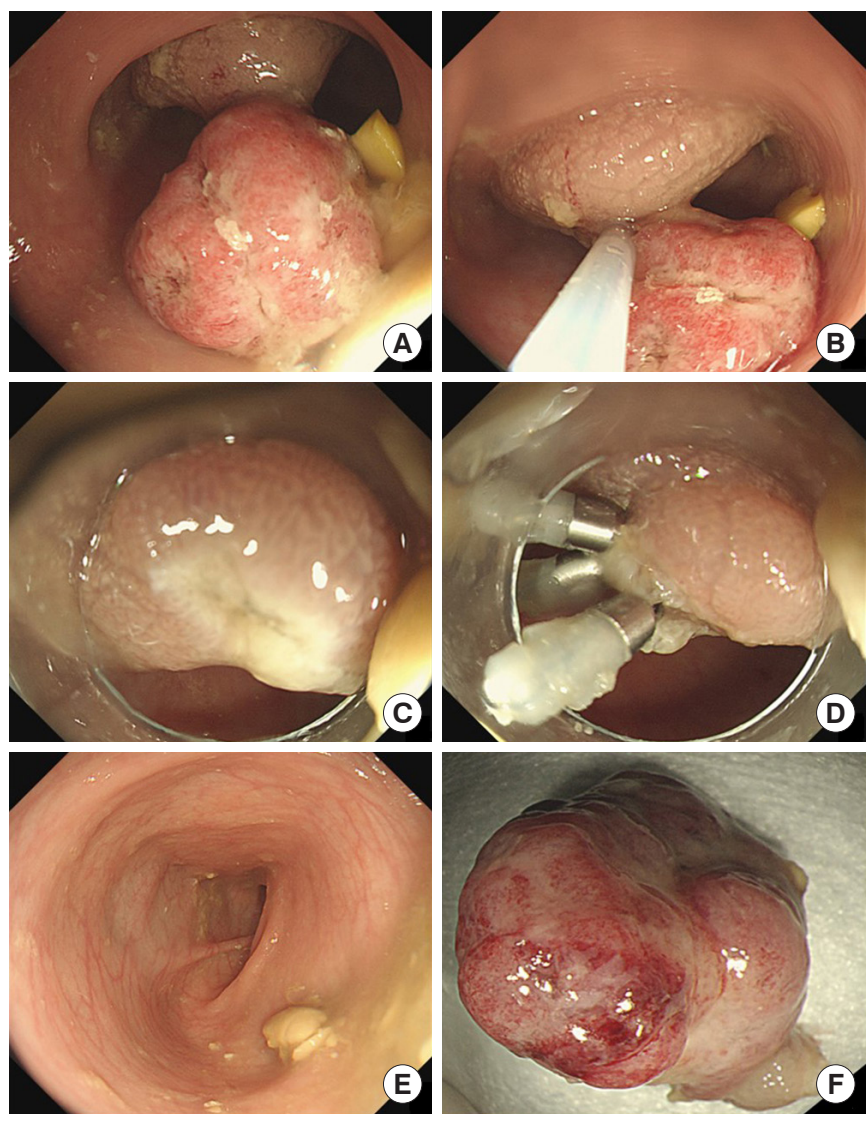

Fig. 2. (A) The polyp was a pedunculated type located $18 \mathrm{~cm}$ above the anal verge. (B) A combination of saline and indigo carmine was used for the submucosal lift and the tip of the snare was anchored on the stalk. (C) Complete removal was achieved after the polypectomy and there was no immediate bleeding. (D) Three clips were applied to the resected site to prevent delayed bleeding. (E) There were no additional polyps in the entire colon. $(\mathrm{F})$ The resected specimen was retrieved and the size was $1.9 \mathrm{~cm}$. 

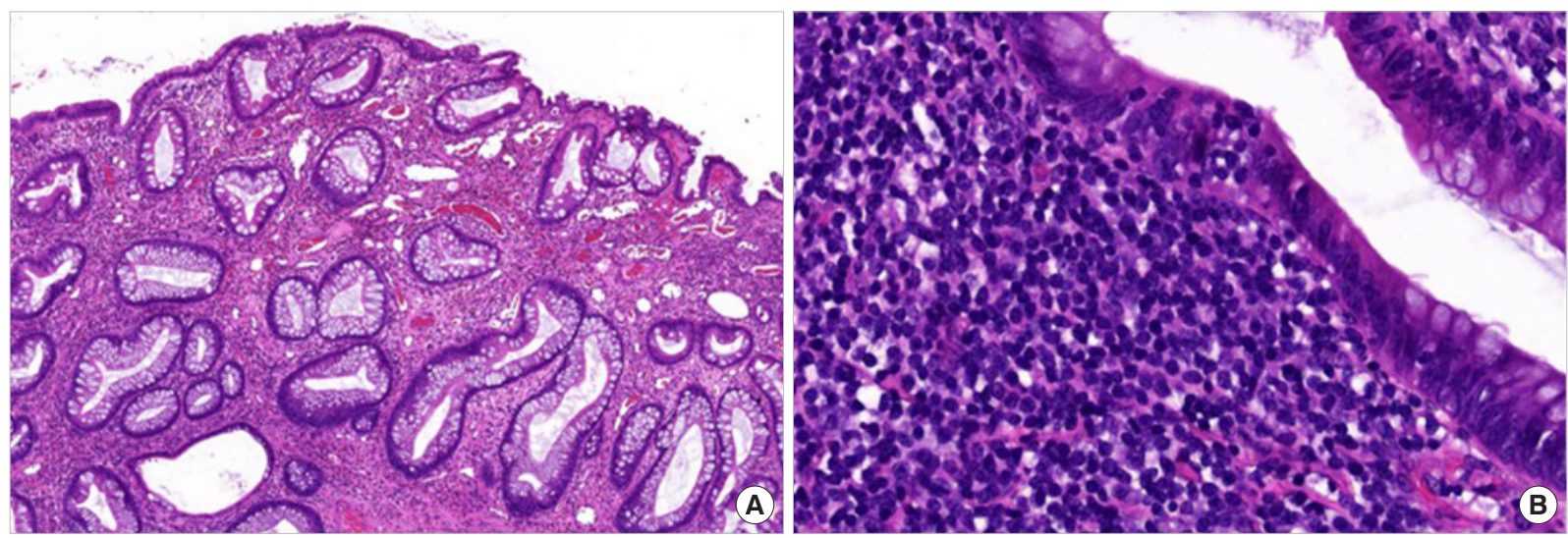

Fig. 3. (A) Histologic findings showed dilated crypts and surface erosion, typical of juvenile polyp (H\&E, $\times 20)$. (B) It showed severe inflammation in the tissue $(\mathrm{H} \& \mathrm{E}, \times 40)$.

ment through the interaction of monocytes and endothelial cells, and through proinflammatory chemokines which activate phagocytes to further promote the outflow of leukocytes to the inflammatory bowel [8]. Detection of this protein in feces is suspected as a result of cell death and destruction [9]. Elevated FC levels are also detectable in infectious diarrhea, eosinophilic colitis, colorectal cancer, and nonsteroidal anti-inflammatory drugs enteropathy $[5,10,11]$.

Recently, FC has been found to be useful for screening juvenile polyp. The increase in FC levels in juvenile polyp is due to the high presence of inflammatory cells within the polyp. Olafsdottir et al. [5] reported that children with juvenile polyp had elevated FC levels, but lower levels than those with active IBD. However, in our case, FC level was as high as those with IBD. Previous studies suggested that the size and number of polyps were associated with an increase in calprotectin $[4,12]$. The larger the number and size of polyps, the higher the calprotectin was increased. However, in our patient, there was only 1 polyp and the size was $1.9 \mathrm{~cm}$, which was smaller than the previous study, but the inflammation level was $>2,500 \mu \mathrm{g} / \mathrm{mL}$. This can be said that regardless of the number or size of the polyps, the severity of inflammation in the polyps itself was associated with an increase in calprotectin.

The use of colonoscopy in children always implies the risk of sedation-related complications. In particular, juvenile polyps occur at a young age between 2 and 5 years of age, and the fact that the lumen of intestine is smaller than that of adults and the need to perform polypectomy is a heavy burden on the gastrointestinal endoscopists. Our patient used an upper gastrointestinal endoscopy because the intestinal diameter was so narrow. Therefore, it is helpful to the operator to accurately predict the presence of juvenile polyp before the procedure and to perform a colonoscopy in a state where the exact location is known. For this reason, abdominal ultrasonography is recently recognized as a primary test for high safety and accuracy as a screening for juvenile polyp in children [13]. In the case of juvenile polyp, they are commonly lo- cated in the left lower colon and rectum $[4,5]$. The causes of false negatives include the operator's skill level, relatively small polyp size, and polyps located in the rectum [14]. According to Qu et al. [13], when enema is performed before abdominal ultrasonography, the polyp detection rate reaches up to $97 \%$. Because our patient did not perform enema prior to ultrasonography, the entire colon including the rectum was evaluated precisely during endoscopy, but there were no additional polyps.

Before the polypectomy, the combination of saline and indigo carmine was used for the submucosal lift, and the clip was fixed at the resected site. In previous studies, this method can reduce postpolypectomy complications [15]. In children, the routine use of prophylactic methods during standard polypectomy procedure can reduce complications.

As in the previous study, in our case, children with juvenile polyp showed normalized FC levels after polypectomy [5]. This suggests that FC is not only useful for screening the existence of juvenile polyp, but also a useful tool for evaluating complete removal of all polyps and the possibility of recurrence of polyps in patients undergoing polypectomy [15].

In conclusion, this is the first case in Korea to show that FC can be used to screen juvenile polyp in children. The polyp can be localized by performing abdominal ultrasonography along with the FC. FC levels can increase with the degree of inflammation regardless of the number or size of the polyps. Complications can be reduced by using prophylactic submucosal lift during the polypectomy. Finally, FC can be useful for diagnosing juvenile polyp before the polypectomy and for follow-up about 1 month after the polypectomy.

\section{CONFLICT OF INTEREST}

No potential conflict of interest relevant to this article was reported. 


\section{REFERENCES}

1. Fox VL, Perros S, Jiang H, Goldsmith JD. Juvenile polyps: recurrence in patients with multiple and solitary polyps. Clin Gastroenterol Hepatol 2010;8:795-9.

2. Adolph VR, Bernabe K. Polyps in children. Clin Colon Rectal Surg 2008;21:280-5.

3. Tringali A, Thomson M, Dumonceau JM, Tavares M, Tabbers MM, Furlano R, et al. Pediatric gastrointestinal endoscopy: European Society of Gastrointestinal Endoscopy (ESGE) and European Society for Paediatric Gastroenterology Hepatology and $\mathrm{Nu}-$ trition (ESPGHAN) Guideline Executive summary. Endoscopy 2017;49:83-91.

4. Pauley-Hunter RJ, Kunnath S, Wolff K, Vanderhoof JA. Fecal calprotectin and pediatric juvenile polyps. J Pediatr Gastroenterol Nutr 2015;60:e30-1.

5. Olafsdottir I, Nemeth A, Lorinc E, Toth E, Agardh D. Value of fecal calprotectin as a biomarker for juvenile polyps in children investigated with colonoscopy. J Pediatr Gastroenterol Nutr 2016; 62:43-6.

6. Roca M, Rodriguez Varela A, Carvajal E, Donat E, Cano F, Armisen A, et al. Fecal calprotectin in healthy children aged 4-16 years. Sci Rep 2020;10:20565.

7. Rugtveit J, Brandtzaeg P, Halstensen TS, Fausa O, Scott H. Increased macrophage subset in inflammatory bowel disease: apparent recruitment from peripheral blood monocytes. Gut 1994; 35:669-74.

8. Nisapakultorn K, Ross KF, Herzberg MC. Calprotectin expression inhibits bacterial binding to mucosal epithelial cells. Infect Immun 2001;69:3692-6.

9. Voganatsi A, Panyutich A, Miyasaki KT, Murthy RK. Mechanism of extracellular release of human neutrophil calprotectin complex. J Leukoc Biol 2001;70:130-4.

10. Chen CC, Huang JL, Chang CJ, Kong MS. Fecal calprotectin as a correlative marker in clinical severity of infectious diarrhea and usefulness in evaluating bacterial or viral pathogens in children. J Pediatr Gastroenterol Nutr 2012;55:541-7.

11. Tibble JA, Sigthorsson G, Foster R, Scott D, Fagerhol MK, Roseth A, et al. High prevalence of NSAID enteropathy as shown by a simple faecal test. Gut 1999;45:362-6.

12. Khan F, Mani H, Chao C, Hourigan S. Fecal calprotectin as a future screening tool for large juvenile polyps. Glob Pediatr Health 2015;2:2333794X15623716.

13. Qu NN, Liu RH, Shi L, Cao XL, Yang YJ, Li J. Sonographic diagnosis of colorectal polyps in children: diagnostic accuracy and multi-factor combination evaluation. Medicine (Baltimore) 2018; 97:e12562.

14. Hosokawa T, Hosokawa M, Tanami Y, Sato Y, Nambu R, Iwama I, et al. Diagnostic performance of ultrasound without any colon preparation for detecting colorectal polyps in pediatric patients. Pediatr Radiol 2019;49:1306-12.

15. Di Nardo G, Esposito F, Ziparo C, Strisciuglio C, Vassallo F, Di Serafino M, et al. Faecal calprotectin and ultrasonography as noninvasive screening tools for detecting colorectal polyps in children with sporadic rectal bleeding: a prospective study. Ital J Pediatr 2020;46:66. 